\title{
THE ENERGY-GROWTH NEXUS WITHIN OIL PRODUCTION AND OIL RENTS CONTEXT
}

José Alberto Fuinhas $^{1} ;$ António Cardoso Marques $^{2} ;$ Matheus Koengkan ${ }^{3} ;$ Renato Santiago $^{4} ;$ Alcino Pinto Couto $^{5}$.

1 - NECE-UBI, CeBER, and Faculty of Economics, University of Coimbra, Portugal.

2 - NECE-UBI and University of Beira Interior, Portuga.

3 - CEFAGE-UE and Department of Economics, University of Évora, Portugal.

4- NECE-UBI and University of Beira Interior.

\section{Abstract}

The per capita primary energy consumption-economic growth nexus is examined in a panel of oil-producing countries over a long period (1970-2015), controlling for the exports of goods and services, the ratio of oil production to oil consumption, the oil rents, and international crude oil prices. It is confirmed that these countries share common spatial patterns, unobserved common factors, or both. A dynamic Driscoll-Kraay estimator, with fixed effects, is used to cope with the heteroskedasticity, contemporaneous correlation, first-order autocorrelation, and cross-sectional dependence. Results prove that energy consumption drives economic growth, but only on the short-run. The ratio of oil production to oil consumption has exerted a positive impact on growth in both the short- and long-run. Oil prices only exert a positive effect on growth in the short-run. Oil rents depress growth, suggesting that oil is more a curse than a blessing for the economies.

Keywords: oil production; oil consumption; oil rents; energy-growth nexus; macro panel.

JEL classification: P18; P28; Q01. 


\section{1 - Introduction}

Most approaches to energy consumption - economic growth nexus concentrate on the extreme case of countries that are oil exporters, neglecting the experience of oil-producing countries with no surplus of oil production. Indeed, the study of the effects of oil on growth has predominantly been limited to oil exporters, more specifically to oil-dependent economies. Moreover, one can observe that fundamental implications of the natural resource economics literature are not considered by the energy-growth nexus studies. It seems to be the case of the surplus oil production and the oil rents arising from them. To the best of our knowledge, the consideration of these dimensions is new in the energy-growth nexus literature. It is expected that they can exert influence in growth performance, shedding light on the dynamic relationships between oil and economic growth, as well as on the direction and magnitude of the causality effects.

The surplus of oil production is not only associated with oil abundance, but also with energy consumption patterns. The interaction between these two variables is very complex and varies in space and time, according to domestic and external conditions, economic and political variables, as well as the dynamics of economic structural change (e.g. Fuinhas et al., 2015; and Al-Mulali, 2011). The way these variables interact explains why some oil-producing countries show high levels of surplus oil production, while others present low or even negative levels.

Another important vehicle for understanding the economic performance of oil-producing countries is the integration of the difference between the value of crude oil production, at world prices, and total costs of production, i.e. the oil rents (World Bank, 2011). The importance of the relationship between this variable and economic growth can be confirmed by the recent literature on the energy-growth nexus that includes the variable oil rents in their estimations (e.g. Ozturk, 2017; Menegaki and Ozturk, 2016). In the literature on natural resources, it is broadly accepted that oil rents are associated with a complex set of economic and political dynamics in oil-rich economies (e.g. Alexeev and Conrad, 2009; Brunnschweiler and Bulte, 2008; and Ross, 2001). A prominent perspective is conveyed by resource curse literature. The Dutch disease hypothesis postulates that an overwhelming dependence on oil rents is harmful to economic growth. Such detrimental effect is generated by a real overvaluation of the exchange rate and its impact on factors reallocations among sectors; favouring the increase of oil and non-tradable sectors and the decline of non-oil tradable sectors (e.g. Ismail, 2010; Larsen, 2004; Torvik, 2001; and Corden and Neary, 1982). Another argument focuses on institutional and political variables as explanatory factors for the inability of oil-producing countries to translate the benefits of oil rent into economic growth (e.g. Frankel, 2010; and Ross, 2001).

Furthermore, the use of oil rents per capita embraces different phenomena: population growth rate, international prices and production costs. The last two variables give us critical information to evaluate the volatility effects of oil markets. The oil producing countries face substantial different break-even points. This fact is explained by sizable differences in oil production costs, and, consequently, reveals differing exposure to oil booms and busts (e.g. Smith, 2014; and STRATFOR, 2014)

In turn, the energy-growth nexus approach offers a different and an aggregated perspective for examining potential oil-growth effects, and the nature of its causality relationships, both in short- and in the long-run. The links between oil production, energy consumption, or oil consumption, and economic growth has been analysed and supported by a vast range of literature (e.g. Djelloul and Talbi, 2017; Saboori et al., 2017; Choi and Yoo, 2016; Fuinhas et al., 2014; Ozturk, 2010). The research of the nexus between energy and economic growth has been mostly based on four cases, namely: (i) Conservation hypothesis; (ii) Growth hypothesis; (iii) Feedback hypothesis; and (iv) Neutrality hypothesis (e.g. Ozturk, 2010; Yuan et al., 2010; Apergis and Payne, 2009; Zhang and Cheng, 2009; Wolde-Rufael, 2009; and Narayan and Smith, 2008)

Nevertheless, this extensive analysis, comprising diverse countries, periods, and econometric methodologies. Considering the nature of the causality relationship, the empirical evidences show outcomes which are far from consensual; and there is no explicit support regarding the direction, or even the existence of a causality in the energy-growth nexus (e.g. Y1ldırım et al., 2014; Ozturk, 2010; and Apergis and Payne, 2009). In particular, concerning oil production, the lack of consensus may be due to four facts. First, the literature on oil production is focused mostly on oil exporting countries. Second, few studies explore the oil production-growth nexus. Third, the literature has neglected the impact of oil production on economic growth for different relative levels of oil production. Fourth, the failure to detect the interaction between energy production and energy consumption. 
Based on cross-country panel, we regressed per capita income on the ratio of oil production to oil consumption, as a proxy of the surplus of oil production, and oil rents per capita, adding control variables and exploring a causality analysis within a multivariate energy-growth nexus framework. This approach aims to explore dynamic adjustments and structural breaks, as well as the causal direction relationships. Hence, the research is applied and empirically supported by: (i) a set of oil-producing countries for which data on oil production and primary energy consumption is available over a long time span (1970 to 2015); and (ii) control of the exports of goods and services, the ratio of oil production to oil consumption, oil rents, and international crude oil prices.

The econometric techniques of the autoregressive distributed lag model are used because they: (i) enable the assessment of short and long-run effects, shedding light on the dynamics of the relationship between drivers; (ii) work upon variables no matters they are $\mathrm{I}(0)$ and/or $\mathrm{I}(1)$ or fractionally integrated; and (iii) can handle relationships ranging from cointegration to long-memory. The focus on oil-producing countries allows a better understanding of three following puzzles. The energy-growth nexus in the context of exploitation of energy resources and consequently the role played by oil rents. The particularities of interactions between oil production and oil consumption on economic growth. The economic growth drivers, controlling for exports of goods and services, oil production, oil consumption, primary energy consumption, and international crude oil prices among countries.

The study is set out as follows. The next sections: presents both data and methodology, as well as, a preliminary analysis of data; discloses the results; centres on the discussion of the main results; and presents the conclusion, policy implications, and further research.

\section{2 - Data and methodology}

The selected oil producing countries meet the following criteria: (i) they have been oil producers during a long period; and (ii) they have data available for the entire period on primary energy consumption, oil consumption, oil production, exports of goods and services, and oil rents. The analysis centres on annual data for the period 1970-2015 and a panel of twenty-one countries, namely: Australia, Algeria, Brazil, Canada, China, Colombia, Denmark, Ecuador, Egypt, India, Indonesia, Italy, Malaysia, Mexico, Norway, Peru, Saudi Arabia, Trinidad and Tobago, United Kingdom, United States, and Venezuela. The source of the raw annual data was the World Bank Data, for gross domestic product (GDP), exports of goods and services, oil rents, and population. The BP Statistical Review of World Energy, June 2014, was the data source for oil consumption, oil production, primary energy consumption, and crude oil prices. The raw data variables used are: (i) GDP (constant local currency unit); (ii) exports of goods and services (\% of GDP); (iii) oil rents (\% of GDP); (iv) population (total of persons); (v) oil consumption (million tonnes); (vi) oil production (million tonnes); (vii) primary energy consumption (million tonnes oil equivalent); and (viii) crude oil prices (US dollars per barrel, 2015). The option of using a constant local currency unit allowed the influence of exchange rates to be circumvented.

All variables, except the ratio of oil production to oil consumption, and crude oil prices, are measured per capita. The option to use per capita values lets us control for the vast disparities in population growth among the countries studied. The variables exports of goods and services per capita (XPC), and oil rents per capita (ORPC) were converted from percentages to constant local currency units to allow the computation of elasticities (long-run) and short-run impacts. The ratio of oil production to oil consumption (SO) - is obtained by dividing the oil production by the oil consumption. This ratio captures the progression of the weight of oil production to oil consumption over time. It is used to control for the heterogeneity of oil producers both through time and as a net oil producer. The SO ratio measures the relative importance of oil production relative to oil consumption expressed in physical units.

Furthermore, the SO ratio is suitable to work with per capita variables. The goal of the SO ratio captures the empirical evidence that energy consumption does not evolve linearly with the oil production. The variables Gross Domestic Product per capita (YPC); primary energy consumption per capita (EPC); and crude oil prices (P) are also used. $\mathrm{P}$ is the "international" spot crude prices and therefore is the same for all countries. After that, the prefixes " $\mathrm{L}$ " and " $\Delta$ " denote natural logarithm and first differences of variables, respectively. 
It is expected that most of these variables have both short- and long-run effects. To handle the dynamics of variables and decompose the total effects in short- and long-run adjustments, a panel with an unrestricted error correction model (UECM) form of an autoregressive distributed lag (ARDL) model is used. Given that the specification of the UECM form of the ARDL model comprises variables that are in natural logarithms, first differences of natural logarithms, and a ratio, then their coefficients are elasticities, short-run impacts, and long-run impacts, respectively. The general ARDL model specification, Eq. (1), is used:

$L Y P C_{i t}=\alpha_{1 i}+\delta_{1 i} \operatorname{TREND}_{t}+\sum_{j=1}^{k} \beta_{11 i j} \mathrm{LYPC}_{i t-j}+\sum_{j=0}^{k} \beta_{12 i j} \mathrm{LEPC}_{i t-j}+\sum_{j=0}^{k} \beta_{13 i j} \mathrm{LXPC}_{i t-j}+\sum_{j=0}^{k} \beta_{14 i j} \mathrm{SO}_{i t-j}+\sum_{j=0}^{k} \beta_{15 i j} \mathrm{LORPC}_{i t-j} \sum_{j=0}^{k} \beta_{16 i j}$

Where $\alpha_{i}$ denotes the intercept, $d_{i}, b_{k i j}, k=1, \ldots, m$, the estimated parameters, and ei the error term. Eq. (1) can be re-parameterised into the general UECM form, Eq. (2), to decompose the dynamic relationships of variables in short- and long-run, as follows:

$\Delta L Y P C_{i t}=\alpha_{2 i}+\delta_{2 i} \operatorname{TREND}_{t}+\sum_{j=1}^{k} \beta_{21 i j} \Delta \mathrm{LYPC}_{i t-j}+\sum_{j=0}^{k} \beta_{22 i j} \Delta \mathrm{LEPC}_{i t-j}+\sum_{j=0}^{k} \beta_{23 i j} \Delta \mathrm{LXPC}_{i t-j}+\sum_{j=0}^{k} \beta_{24 i j} \Delta \mathrm{SO}_{i t-j}+\sum_{j=0}^{k} \beta_{25 i j} \Delta \mathrm{LORPC}$

$$
+\gamma_{21 i} \mathrm{LYPC}_{i t-1}+\gamma_{22 i} \mathrm{LEPC}_{i t-1}+\gamma_{23 i} \mathrm{LXPC}_{i t-1}+\gamma_{24 i} \mathrm{SO}_{i t-1}+\gamma_{25 i} \mathrm{LORPC}_{i t-1}+\gamma_{26 i} \mathrm{LP}_{i t-1}+\varepsilon_{2 i t}
$$

Where $\alpha_{i}$ denotes the intercept, $\delta_{i}, \beta_{i j}$, and $\gamma_{i m}$, the estimated parameters, and $\epsilon i$ the error term. The descriptive statistics, the cross-section dependence (CSD), and the order of integration of the variables are analysed to identify the features of both series and crosses. Table 1 reveals both the descriptive statistics, the coefficients of variations $(\mathrm{CV})$, and the CSD of the variables.

Table 1 - Descriptive statistics and CSD

\begin{tabular}{lllllll|llll}
\hline \multirow{2}{*}{ Variables } & \multicolumn{9}{c}{ Descriptive statistics } & \multicolumn{3}{c}{ CSD } \\
\cline { 2 - 11 } & Obs & Mean & Std.Dev. & Min. & Max. & CV & CD-test & Corr & Abs (Corr) \\
\hline LYPC & 965 & 9.0541 & 1.3663 & 5.4307 & 11.4251 & 0.1509 & 64.48 & $* * *$ & 0.661 & 0.759 \\
\hline LEPC & 966 & -13.3036 & 1.2061 & -16.4374 & -10.9748 & -0.0907 & 48.14 & $* * *$ & 0.494 & 0.698 \\
\hline LXPC & 965 & 7.5718 & 1.6872 & 1.7385 & 10.6388 & 0.2228 & 66.07 & $* * *$ & 0.678 & 0.717 \\
\hline SO & 963 & 2.7475 & 3.4843 & 0.0015 & 23.7244 & 1.2682 & 1.87 & $*$ & 0.019 & 0.477 \\
\hline LORPC & 956 & 4.8175 & 2.5832 & -7.8636 & 9.9213 & 0.5362 & 78.11 & $* * *$ & 0.802 & 0.804 \\
\hline LP & 966 & 3.8244 & 0.6109 & 2.3962 & 4.7641 & 0.1597 & 97.37 & $* * *$ & 1.000 & 1.000 \\
\hline$\Delta$ LYPC & 944 & 0.0216 & 0.0384 & -0.1734 & 0.2149 & 1.7790 & 12.58 & $* * *$ & 0.131 & 0.208 \\
\hline$\Delta$ LEPC & 945 & 0.0206 & 0.0534 & -0.2831 & 0.3192 & 2.5978 & 9.07 & $* * *$ & 0.094 & 0.168 \\
\hline$\Delta$ LXPC & 944 & 0.0327 & 0.1348 & -0.6323 & 0.6379 & 4.1171 & 27.78 & $* * *$ & 0.289 & 0.311 \\
\hline$\Delta$ SO & 942 & -0.0351 & 0.6708 & -7.5098 & 4.8048 & -19.1317 & 0.75 & & 0.008 & 0.156 \\
\hline$\Delta$ LORPC & 935 & 0.1418 & 0.8154 & -2.6659 & 5.8991 & 5.7513 & 75.76 & $* * *$ & 0.787 & 0.787 \\
\hline$\Delta$ LP & 945 & 0.0347 & 0.3070 & -0.6655 & 1.1546 & 8.8411 & 96.28 & $* * *$ & 1.000 & 1.000 \\
\hline
\end{tabular}

Notes: $\mathrm{CV}$ denote coefficient of variations, i.e. the ratio of the standard deviation to the mean; $\mathrm{CD}$ test has $\mathrm{N}(0,1)$ distribution, under the H0: cross-section independence. $* * *, *$ denotes significant at $1 \%$ and $10 \%$ levels. The Stata command xtcd was used to achieve the results for CSD.

The CV points to the high volatility of $\Delta \mathrm{SO}, \Delta \mathrm{LP}, \Delta \mathrm{LORPC}$, and $\Delta \mathrm{LXPC}$ (see Table 1). Of particular interest to our analysis, the economic growth, and the primary energy consumption grew almost the same during this period. The presence of CSD shows interdependence between the cross-sections attributable to countries sharing common shocks (e.g. Eberhardt, 2011). The test for CSD (CD-test) strongly suggests that countries share common paths for all variables except the ratio of oil production to oil consumption, either as a ratio or first differences of the ratio. Indeed, the absence of CSD for the variables $\Delta \mathrm{SO}$, point to oil producing countries reacting independently.

The correlation values and both the individual and mean variance inflation factor (VIF) statistics, indicate that multicollinearity is not a cause for concern (see Table 2). Nevertheless, three features deserve comment. On the one hand, the correlation of exports with primary energy consumption, and between oil rents and exports. On the other hand, the correlation between international crude prices inflation and the rate of variation of oil rents. 
Table 2 - Matrices of correlations and VIF statistics

\begin{tabular}{|c|c|c|c|c|c|c|c|c|c|c|c|}
\hline & \multicolumn{2}{|c|}{ LYPC } & \multicolumn{2}{|c|}{ LEPC } & \multicolumn{2}{|c|}{ LXPC } & \multicolumn{2}{|c|}{ so } & \multicolumn{2}{|c|}{ LORPC } & \multirow[t]{2}{*}{ LP } \\
\hline LYPC & 1.0000 & & & & & & & & & & \\
\hline LEPC & 0.8880 & $* * *$ & 1.0000 & & & & & & & & \\
\hline LXPC & 0.9373 & $* * *$ & 0.8665 & $* * *$ & 1.0000 & & & & & & \\
\hline so & 0.0955 & $* *$ & 0.1050 & $* *$ & 0.2100 & $* * *$ & 1.0000 & & & & \\
\hline LORPC & 0.3885 & $* * *$ & 0.4761 & $* * *$ & 0.5031 & $* * *$ & 0.3933 & $* * *$ & 1.0000 & & \\
\hline LP & 0.0999 & $* *$ & 0.1009 & $* *$ & 0.1475 & $* * *$ & -0.0917 & $* * *$ & 0.4798 & $* * *$ & 1.0000 \\
\hline VIF & & & \multicolumn{2}{|c|}{4.42} & \multicolumn{2}{|c|}{4.39} & \multicolumn{2}{|c|}{1.45} & \multicolumn{2}{|c|}{2.33} & 1.57 \\
\hline Mean VIF & \multicolumn{11}{|c|}{2.83} \\
\hline & \multicolumn{2}{|c|}{$\Delta$ LYPC } & \multicolumn{2}{|c|}{$\Delta$ LEPC } & \multicolumn{2}{|c|}{$\Delta$ LXPC } & $\Delta$ so & \multicolumn{2}{|c|}{$\triangle$ LORPC } & \multicolumn{2}{|c|}{$\Delta \mathrm{LP}$} \\
\hline$\Delta \mathrm{LYPC}$ & 1.0000 & & & & & & & & & & \\
\hline$\triangle \mathrm{LEPC}$ & 0.4109 & $* * *$ & 1.0000 & & & & & & & & \\
\hline$\Delta \mathrm{LXPC}$ & 0.2803 & $* * *$ & 0.1023 & $* * *$ & 1.0000 & & & & & & \\
\hline$\Delta \mathrm{so}$ & 0.2497 & $* * *$ & -0.2345 & $* * *$ & 0.2302 & $* * *$ & 1.0000 & & & & \\
\hline$\triangle$ LORPC & 0.1310 & $* * *$ & 0.0853 & $* * *$ & 0.3764 & $* * *$ & 0.0636 & * & 1.0000 & & \\
\hline$\Delta \mathrm{LP}$ & 0.1560 & $* * *$ & 0.1083 & $* * *$ & 0.4040 & $* * *$ & -0.0383 & & 0.7671 & $* * *$ & 1.0000 \\
\hline VIF & & & \multicolumn{2}{|c|}{1.09} & \multicolumn{2}{|c|}{1.32} & \multicolumn{2}{|c|}{1.18} & \multicolumn{2}{|c|}{2.50} & 2.62 \\
\hline Mean VIF & & & & & & 1.74 & & & & & \\
\hline
\end{tabular}

Notes: $* * *, * *, *$ denote statistically significant at $1 \%, 5 \%$, and $10 \%$ level, respectively.

To assess the order of integration of the variables, the first-generation panel unit root tests of LLC (Levin, Lin and Chu, 2002), ADF-Fisher (Maddala and Wu, 1999) and ADF-Choi (Choi, 2001); and the second-generation unit roots test, of the CIPS (Pesaran, 2007) were applied.

Table 3 - Unit root tests

\begin{tabular}{|c|c|c|c|c|c|c|c|c|c|c|}
\hline \multirow[b]{4}{*}{ LYPC } & \multicolumn{6}{|c|}{$1^{s t}$ generation } & \multirow{2}{*}{\multicolumn{4}{|c|}{$\begin{array}{c}2^{\text {nd }} \text { generation } \\
\text { CIPS (Zt-bar) }\end{array}$}} \\
\hline & \multicolumn{2}{|c|}{ LLC } & \multicolumn{2}{|c|}{ ADF-Fisher } & \multicolumn{2}{|c|}{ ADF-Choi } & & & & \\
\hline & \multicolumn{6}{|c|}{ Individual intercept and trend } & \multicolumn{3}{|c|}{ without trend } & with trend \\
\hline & 0.7987 & & 42.3201 & & 0.1801 & & 1.924 & & 0.325 & \\
\hline LEPC & 2.0583 & & 6.7186 & & 4.7924 & & -0.576 & & -0.270 & \\
\hline LXPC & -2.8700 & $* * *$ & 68.161 & $* * *$ & -9.901 & $* * *$ & -1.051 & & -0.591 & \\
\hline so & 0.0748 & & 16.677 & & 2.0449 & & 0.256 & & 0.190 & \\
\hline ORPC & -4.9016 & $* * *$ & 162.243 & $* * *$ & -9.3182 & $* * *$ & -5.585 & $* * *$ & -6.388 & $* * *$ \\
\hline LP & -0.5957 & & 38.1083 & & -1.1184 & & n.a. & & n.a & \\
\hline$\Delta$ LYPC & -17.3568 & $* * *$ & 244.927 & $* * *$ & -12.6256 & $* * *$ & -8.855 & $* * *$ & -8.521 & $* * *$ \\
\hline$\triangle$ LEPC & -14.5057 & $* * *$ & 158.669 & $* * *$ & -9.1548 & $* * *$ & -11.863 & $* * *$ & -10.193 & $* * *$ \\
\hline$\Delta \mathrm{LXPC}$ & -19.0610 & $* * *$ & 369.642 & $* * *$ & -16.5628 & $* * *$ & -12.178 & $* * *$ & -10.496 & $* * *$ \\
\hline$\Delta \mathrm{so}$ & -6.5663 & $* * *$ & 263.329 & $* * *$ & -13.2689 & $* * *$ & -9.889 & $* * *$ & -10.088 & $* * *$ \\
\hline$\triangle \mathrm{LORPC}$ & -10.0054 & $* * *$ & 233.096 & $* * *$ & -12.1972 & $* * *$ & -14.487 & $* * *$ & -12.502 & $* * *$ \\
\hline$\Delta \mathrm{LP}$ & -4.7343 & $* * *$ & 214.727 & $* * *$ & -11.5065 & $* * *$ & n.a. & & n.a & \\
\hline
\end{tabular}

Notes: $* * *, * *, *$ denote statistically significant at $1 \%, 5 \%$, and $10 \%$ level, respectively; n.a. denotes not applicable; the null hypotheses are as follows. LLC: unit root (common unit root process); this unit root test controls for individual effects, individual linear trends, has a lag length 1, and Newey-West automatic bandwidth selection and Bartlett kernel; ADF-Fisher and ADF-Choi: unit root (individual unit root process); this unit root test controls for individual effects, individual linear trends, has a lag length 1; first generation tests follow the option "individual intercept and trend", which was decided after a visual inspection of the series; Pesaran (2007) Panel Unit Root test (CIPS): series are I(1); the EViews was used to compute LLC, ADF-Fisher, and ADF-Choi; and the Stata command multipurt was used to compute CIPS 
The LLC and the ADF tests are consensual in appointing variables LXPC and LORPC as integrated series of order one I(1), and LYPC, LEPC, SO and LP as stationary (see Table 3). The CIPS test appoints for the stationarity of LORPC. It is worthwhile to note that the variables LP and $\triangle$ LP are common to all countries, which makes the applicability of CIPS worthless. We can assume that the order of integration of variables is, at most, I(1).

\section{3 - Results}

As the order of integration of the variables can be $\mathrm{I}(0)$, borderline $\mathrm{I}(0) / \mathrm{I}(1)$ or $\mathrm{I}(1)$, and the presence of CSD was detected, the second-generation cointegration test of Westerlund (2007) was computed (see Table 4). As the variables SO and LORPC may be proxies of LP in the long-run for oil-producing countries, cointegration was tested for the general model that includes all variables (LYPC LEPC LXPC SO LORPC LP), and for two restricted ones (LYPC LXPC SO LORPC, and LYPC LXPC LP). The presence of cointegration is explicitly rejected, both considering the panel and considering each country individually

Table 4 - Westerlund (2007) cointegration tests

\begin{tabular}{lllll}
\hline Variables & \multicolumn{3}{c}{ LYPC; LEPC; LXPC; SO; LORPC; and LP } \\
\cline { 2 - 5 } Statistic & Value & Z-value & P-value & Robust P-value \\
\hline $\mathrm{Gt}$ & -2.632 & 1.906 & 0.972 & 0.378 \\
$\mathrm{Ga}$ & -10.266 & 4.472 & 1.000 & 0.841 \\
$\mathrm{Pt}$ & -11.416 & 1.355 & 0.912 & 0.299 \\
$\mathrm{~Pa}$ & -8.748 & 3.522 & 1.000 & 0.575 \\
\hline Variables & & & LYPC; $\mathbf{L X P C}$; SO; and LORPC \\
Statistic & Value & Z-value & P-value & Robust P-value \\
Gt & -2.292 & 1.290 & 0.902 & 0.625 \\
Ga & -10.964 & 1.668 & 0.952 & 0.515 \\
Pt & -10.824 & -0.378 & 0.353 & 0.346 \\
Pa & -10.681 & -0.131 & 0.448 & 0.240 \\
\hline
\end{tabular}

Notes: Bootstrapping regression with 800 reps; $\mathrm{H}_{0}$ : no cointegration; Gt and Ga test the cointegration for each country individually, and Pt and Pa test the cointegration of the panel as a whole; and the Stata command xtwest (with the options constant and trend) was used.

The presence of fixed effects (FE) ought to be tested against random effects (RE). For the RE model, in Eq. (3), the error term assumes the form $\varepsilon_{i t}=\mu_{i}+\omega_{i t}$, where $\mu_{t}$ denotes the N-1 country-specific effects, and $\omega_{i t}$ are the independent and identically distributed errors. In conformity, Eq. (2) is converted in Eq. (3):

$\Delta L Y P C_{i t}=\alpha_{3 i}+\delta_{3 i} T R E N D_{t}+\sum_{j=1}^{k} \beta_{31 i j} \Delta L Y P C_{i t-j}+\sum_{j=0}^{k} \beta_{32 i j} \Delta L E P C_{i t-j}+\sum_{j=0}^{k} \beta_{33 i j} \Delta L X P C_{i t-j}+\sum_{j=0}^{k} \beta_{34 i j} \Delta S O_{i t-j}+\sum_{j=0}^{k} \beta_{35 i j} \Delta L O R F$

$$
+\gamma_{31 i} L Y P C_{i t-1}+\gamma_{32 i} L E P C_{i t-1}+\gamma_{33 i} L X P C_{i t-1}+\gamma_{34 i} S O_{i t-1}+\gamma_{35 i} L O R P C_{i t-1}+\gamma_{36 i} L P_{i t-1}+\mu_{i}+\omega_{i t}
$$

where $\alpha_{3 i}$ denotes the intercept, $\delta_{3 i}, \beta_{3 k i j}, k=1, \ldots, m, \gamma_{3 i m}$ the estimated parameters, and $\varepsilon_{3 i}$ the error term.

To test RE against FE specifications between Eq. (2) and Eq. (3), the Hausman test, which has a null hypothesis that the best is RE, was used. Both in model 1 as in model 2 the Hausman results are statistically highly significant $\left(C h i_{(12)}^{2}=134.96\right.$ and $C h i_{(12)}^{2}=94.85$, respectively), supporting that the FE specification is preferable relatively to the RE specification.

The heterogeneity of parameter slopes was assed testing the Mean Group (MG), and the Pooled Mean Group (PMG) against the FE estimator. The decision about the most suitable model is made by computing a Hausman test confronting the three specifications. The long-run variable LEPC reveal no statistical significance in all estimated models.

Table 5 shows the results of the estimations for the MG, PMG and FE models, as well as the outcomes of the Hausman tests. The result suggests the FE as the appropriate estimator, indicating that the panel is homogeneous, meaning that oil producers share common coefficients, and can be treated as a group. 
Table 5 - Heterogeneous estimators and Hausman tests.

\begin{tabular}{|c|c|c|c|c|c|c|}
\hline \multirow[b]{3}{*}{ Constant } & \multicolumn{4}{|c|}{ Model 1 (Dependent Variable $\triangle$ LYPC) } & & \\
\hline & \multicolumn{2}{|c|}{ MG } & \multicolumn{2}{|c|}{ PMG } & \multicolumn{2}{|c|}{ DFE } \\
\hline & 0.5036 & $* * *$ & 0.2263 & $* * *$ & 0.2741 & $* * *$ \\
\hline$\triangle \mathrm{LEPC}$ & 0.3192 & $* * *$ & 0.3378 & $* * *$ & 0.3004 & $* * *$ \\
\hline$\Delta \mathrm{LXPC}$ & 0.0613 & $* * *$ & 0.0576 & $* * *$ & 0.0354 & $* * *$ \\
\hline$\Delta$ so & 0.0160 & & 0.0207 & & 0.0196 & $* * *$ \\
\hline$\triangle$ LORPC & -0.0018 & & -0.0022 & & -0.0044 & $* *$ \\
\hline$\Delta \mathrm{LP}$ & 0.0071 & & 0.0076 & & 0.0136 & $* * *$ \\
\hline $\mathrm{ECM}$ & -0.0988 & $* * *$ & -0.0589 & $* * *$ & -0.0677 & $* * *$ \\
\hline $\operatorname{LXPC}(-1)$ & 3.4538 & & 0.7340 & $* * *$ & 0.7128 & $* * *$ \\
\hline SO $(-1)$ & -0.7469 & & 0.0023 & & 0.0133 & * \\
\hline \multirow[t]{2}{*}{ LORPC $(-1)$} & -0.2696 & & -0.0273 & $* * *$ & -0.0430 & $* * *$ \\
\hline & \multicolumn{2}{|c|}{ MG $v s$ PMG } & \multicolumn{2}{|c|}{ PMG vs DFE } & \multicolumn{2}{|c|}{ MG $v s$ DFE } \\
\hline \multirow[t]{3}{*}{ Hausman tests } & \multicolumn{2}{|c|}{$C h i_{(10)}^{2}=$ n.a. } & \multicolumn{2}{|c|}{$C h i_{(10)}^{2}=0.00$} & \multicolumn{2}{|c|}{$C h i_{(12)}^{2}=0.00$} \\
\hline & \multicolumn{4}{|c|}{ Model 2 (Dependent Variable $\Delta$ LYPC) } & & \\
\hline & \multicolumn{2}{|c|}{ MG } & \multicolumn{2}{|c|}{ PMG } & \multicolumn{2}{|c|}{ DFE } \\
\hline Constant & 0.5662 & $* * *$ & 0.2101 & $* * *$ & 0.2776 & $* * *$ \\
\hline$\triangle \mathrm{LEPC}$ & 0.3217 & $* * *$ & 0.3377 & $* * *$ & 0.3055 & $* * *$ \\
\hline$\triangle \mathrm{LXPC}$ & 0.0643 & $* * *$ & 0.0555 & $* * *$ & 0.0333 & $* * *$ \\
\hline$\Delta$ so & 0.0180 & & 0.0195 & & 0.0186 & $* * *$ \\
\hline$\triangle \mathrm{LORPC}$ & -0.0006 & & -0.0012 & & -0.0003 & $* *$ \\
\hline$\Delta \mathrm{LP}$ & 0.0048 & & 0.0058 & & 0.0085 & * \\
\hline $\mathrm{ECM}$ & -0.1113 & $* * *$ & -0.0558 & $* * *$ & -0.06967 & $* * *$ \\
\hline $\operatorname{LXPC}(-1)$ & 0.5667 & $* * *$ & 0.7686 & $* * *$ & 0.6967 & $* * *$ \\
\hline \multirow[t]{2}{*}{ LP (-1) } & -0.0509 & & -0.0875 & $* * *$ & -0.0716 & $* *$ \\
\hline & \multicolumn{2}{|c|}{ MG $v s$ PMG } & \multicolumn{2}{|c|}{ PMG vs DFE } & \multicolumn{2}{|c|}{ MG $v s$ DFE } \\
\hline Hausman tests & \multicolumn{2}{|c|}{$C h i_{(9)}^{2}=7.79$} & \multicolumn{2}{|c|}{$C h i_{(9)}^{2}=0.01$} & \multicolumn{2}{|c|}{$C h i_{(9)}^{2}=0.00$} \\
\hline
\end{tabular}

Notes: $* * *, * *, *$ denote significant at $1 \%, 5 \%$, and $10 \%$ level, respectively; Hausman results for $\mathrm{H}_{0}$ : difference in coefficients not systematic; ECM denotes error correction mechanism; the long-run parameters are computed elasticities; the Stata commands $x$ tpmg, and hausman (with the options sigmamore, alleqs, and constant) were used; n.a. denotes not available.

Furthermore, as seen earlier the analysis of MG, PMG and FE models indicates that in long-run two groups of variables could be alternative, as the variables SO and LORPC seem to to be proxies of LP. To check this former alternative two models (Model 1 and Model 2) are presented.

The Model 1, Eq. (4), uses the variables LXPC, SO, and LORPC in the long-run:

$\Delta L Y P C_{i t}=\alpha_{4 i}+\sum_{j=1}^{k} \beta_{41 i j} \Delta L Y P C_{i t-j}+\sum_{j=0}^{k} \beta_{42 i j} \Delta L E P C_{i t-j}+\sum_{j=0}^{k} \beta_{43 i j} \Delta L X P C_{i t-j} \Delta L X P C_{i t-j}+\sum_{j=0}^{k} \beta_{44 i j} \Delta S O_{i t-j}+\sum_{j=0}^{k} \beta_{45 i j} \Delta L O R P C_{i 1}$ $+\gamma_{41 i} L Y P C_{i t-1}+\gamma_{42 i} L X P C_{i t-1}+\gamma_{43 i} S O_{i t-1}+\gamma_{44 i} L O R P C_{i t-1}+\varepsilon_{4 i t}$

Where $\alpha_{4 i}$ denotes the intercept, $\beta_{4 k i j}, k=1, \ldots, m, \gamma_{4 n i}, n=1, \ldots, v$, the estimated parameters, and $\varepsilon_{4 i}$ the error term. 
The Model 2, Eq. (5), uses the variables LXPC, and LP in the long-run:

$$
\begin{aligned}
& \Delta L Y P C_{i t} \alpha_{5 i}+\sum_{j=1}^{k} \beta_{51 i j} \Delta L Y P C_{i t-j}+\sum_{j=0}^{k}+\sum_{j=0}^{k} \beta_{52 i j} \Delta L E P C_{i t-j}+\sum_{j=0}^{k} \beta_{53 i j} \Delta L X P C_{i t-j}+\sum_{j=0}^{k} \beta_{54 i j} \Delta S O_{i t-j}+\sum_{j=0}^{k} \beta_{55 i j} \Delta L O R P C_{i t-j}+\sum_{j=0}^{k} \\
& +\gamma_{51 i} L Y P C_{i t-1}+\gamma_{52 i} L X P C_{i t-1}+\gamma_{53 i} L P_{i t-1}+\varepsilon_{5 i t}
\end{aligned}
$$

Where $\alpha_{5 i}$ denotes the intercept, $\beta_{5 k i j}, k=1, \ldots, m, \gamma_{5 n i}, n=1, \ldots, v$, the estimated parameters, and $\varepsilon_{5 i}$ the error term.

To back up the significance of FE parameters, a battery of specification tests were conducted, specifically on group wise heteroskedasticity of the fixed effects (modified Wald test), contemporaneous correlation among cross-sections (Pesaran test), non-correlation of variances across individuals (Breusch-Pagan Lagrangian Multiplier test), and autocorrelation to check the existence of serial correlation (Wooldridge test). The specification tests (Table 6) point to the presence of heteroskedasticity, of contemporaneous correlation, and first-order autocorrelation. The Breusch-Pagan LM test the hypothesis that the residuals are correlated cannot be carried out, given that the correlation matrix of residuals is singular.

\begin{tabular}{|c|c|c|c|}
\hline \multirow{3}{*}{ Statistics } & \multicolumn{3}{|c|}{ Model 1} \\
\hline & Modified Wald's test & Pesaran's test & Wooldridge's test \\
\hline & $C h i_{(21)}^{2}=653.80 * * *$ & $2.254 * *$ & $F_{(1,20)}=44.802 * * *$ \\
\hline \multicolumn{4}{|c|}{ Model 2} \\
\hline \multirow{2}{*}{ Statistics } & Modified Wald's test & Pesaran's test & Wooldridge's test \\
\hline & $C h i_{(21)}^{2}=702.85 * * *$ & $3.718 * * *$ & $F_{(1,20)}=51.170 * * *$ \\
\hline
\end{tabular}

Table 6 - Specification tests.

Note: $* * *, * *$, denote statistically significant at $1 \%$ and $5 \%$ level, respectively; results for $H_{0}$ of Modified Wald test: $\sigma(i)^{2}=\sigma^{2}$ for all I; results for $H_{0}$ of Pesaran's test: residuals are not correlated; results for $H_{0}$ of Wooldridge test: no first-order autocorrelation.

To handle heteroskedasticity, contemporaneous correlation, first-order autocorrelation, and cross-sectional dependence in the context of a long time span, the Driscoll and Kraay (1998) estimator were used. This estimator is a matrix estimator that generates robust standard errors for several phenomena found in the sample errors. As a benchmark, the FE estimator and the FE estimator with robust standard errors (to control for the heteroskedasticity) are shown in Table 7.

\begin{tabular}{|c|c|c|c|c|c|c|c|c|}
\hline \multicolumn{9}{|c|}{ Dependent Variable $\triangle \mathrm{LYPC}$} \\
\hline & \multicolumn{4}{|c|}{ Model 1} & \multicolumn{4}{|c|}{ Model 2} \\
\hline & & FE & $\begin{array}{l}\mathrm{FE} \\
\text { Rob. }\end{array}$ & FE D.-K. & & $\mathrm{FE}$ & $\begin{array}{l}\mathrm{FE} \\
\text { Rob. }\end{array}$ & FE D.-K. \\
\hline Constant & 0.2741 & $* * *$ & $* * *$ & $* * *$ & 0.2776 & $* * *$ & $* * *$ & $* * *$ \\
\hline$\triangle \mathrm{LEPC}$ & 0.3004 & $* * *$ & $* * *$ & $* * *$ & 0.3055 & $* * *$ & $* * *$ & $* * *$ \\
\hline$\triangle \mathrm{LXPC}$ & 0.0354 & $* * *$ & $* *$ & $* * *$ & 0.0333 & $* * *$ & $*$ & $* *$ \\
\hline$\Delta \mathrm{SO}$ & 0.0196 & $* * *$ & $* * *$ & $* * *$ & 0.0186 & $* * *$ & $* * *$ & $* * *$ \\
\hline$\triangle \mathrm{LORPC}$ & -0.0044 & $* *$ & $* *$ & & -0.0003 & & & \\
\hline$\Delta \mathrm{LP}$ & 0.0136 & $* * *$ & * & $*$ & 0.0085 & * & & \\
\hline LYPC(-1) & -0.0677 & $* * *$ & $* * *$ & $* * *$ & -0.0649 & $* * *$ & $* * *$ & $* * *$ \\
\hline LXPC(-1) & 0.0483 & $* * *$ & $* * *$ & $* * *$ & 0.0452 & $* * *$ & $* * *$ & $* * *$ \\
\hline $\mathrm{SO}(-1)$ & 0.0009 & $*$ & $* *$ & & & & & \\
\hline LORPC(-1) & -0.0029 & $* * *$ & $* * *$ & $* * *$ & & & & \\
\hline \multirow[t]{2}{*}{$\mathrm{LP}(-1)$} & & & & & -0.0046 & $* * *$ & $* * *$ & * \\
\hline & \multicolumn{4}{|c|}{ Statistics } & \multicolumn{4}{|c|}{ Statistics } \\
\hline $\mathrm{N}$ & & 935 & 935 & 935 & & 935 & 935 & 935 \\
\hline$R^{2}$ & & 0.3946 & 0.3946 & & & 0.3821 & 0.3821 & \\
\hline$R_{a}^{2}$ & & 0.3752 & 0.3887 & & & 0.3630 & 0.3767 & \\
\hline F & & 65.5434 & 17.2950 & 25.8571 & & 70.0243 & 11.5707 & 32.7780 \\
\hline
\end{tabular}

Table 7. Estimation results.

Notes: $* * *, * *, *$ denote statistically significant at $1 \%, 5 \%$ and $10 \%$ level, respectively; and the Stata commands $x$ treg, and $x t s c c$ were used.

Table 8 exhibits the short-run impacts and long-run elasticities/impacts for the models FE, FE robust (FE Rob.), and FE Driscoll and Kraay (FE D.-K.). The 
long-run elasticities/impacts were not observed directly on the estimates. As such, they must be computed by dividing the coefficient of the variables by the coefficient of LYPC, both lagged once and multiplying the ratio by -1 .

Table 8 - Elasticities, impacts, and speed of adjustment.

\begin{tabular}{|c|c|c|c|c|c|c|c|c|}
\hline \multicolumn{9}{|c|}{ Dependent Variable $\triangle$ LYPC } \\
\hline & \multicolumn{4}{|c|}{ Model 1} & \multicolumn{4}{|c|}{ Model 2} \\
\hline & & $\mathrm{FE}$ & $\begin{array}{l}\mathrm{FE} \\
\text { Rob. }\end{array}$ & FE D.-K. & & $\mathrm{FE}$ & $\begin{array}{l}\mathrm{FE} \\
\text { Rob. }\end{array}$ & FE D.-K \\
\hline$\triangle \mathrm{LEPC}$ & 0.3004 & $* * *$ & $* * *$ & $* * *$ & 0.3055 & $* * *$ & $* * *$ & $* * *$ \\
\hline$\triangle \mathrm{LXPC}$ & 0.0354 & $* * *$ & $* *$ & $* * *$ & 0.0333 & $* * *$ & * & $* *$ \\
\hline$\Delta \mathrm{SO}$ & 0.0196 & $* * *$ & $* * *$ & $* * *$ & 0.0186 & $* * *$ & $* * *$ & $* * *$ \\
\hline$\triangle \mathrm{LORPC}$ & -0.0044 & ** & $* *$ & & -0.0003 & & & \\
\hline$\Delta \mathrm{LP}$ & 0.0136 & $* * *$ & * & * & 0.0085 & * & & \\
\hline LXPC(-1) & 0.7128 & $* * *$ & $* * *$ & $* * *$ & 0.6967 & $* * *$ & $* * *$ & $* * *$ \\
\hline $\mathrm{SO}(-1)$ & 0.0133 & * & $* *$ & & & & & \\
\hline LORPC(-1) & -0.0430 & $* * *$ & $* * *$ & $* * *$ & & & & \\
\hline $\mathrm{LP}(-1)$ & & & & & -0.0715 & $* *$ & $* * *$ & * \\
\hline $\mathrm{ECM}$ & -0.0677 & $* * *$ & $* * *$ & $* * *$ & -0.0649 & $* * *$ & $* * *$ & $* * *$ \\
\hline
\end{tabular}

Notes: *, denote statistically significant at $1 \%$ and $5 \%$ level, respectively. ECM denotes the coefficient of the variable LYPC lagged once.

Given the fact that there are different effects on the short- and long-run, the dynamic panel techniques were shown to be appropriate. The speed of adjustment, i.e. the ECM term, is low, less than 7\% (see Table 8), implying that shocks require a longer adjustment time to return to equilibrium.

Moreover, to examine both the asymmetric responses of oil rents per capita (ORPC) and the ratio of oil production to oil consumption (SO), to gross domestic product per capita (YPC), both in the short- and long-run in model 1, and only in the short-run in model 2, the nonlinear ARDL model was used. In the literature, the nonlinear ARDL model is derived from the basic linear error correction model (ECM) (Jammazi et al., 2015).

The nonlinear ARDL model following the asymmetric long-run regression:

$$
y_{t}=\beta_{t}^{+} x_{t}^{+}+\beta_{t}^{-} x_{t}^{-}+\mu_{t}
$$

Where $\beta_{t}^{+}$and $\beta_{t}^{-}$are the associated long-run parameters, $\mu_{t}$ is an i.i.d. process with zero mean and finite variance, and $x_{t}$ is decomposed as:

$$
x_{t}=x_{0}+x_{t}^{+}+x_{t}^{-}
$$

Where $x_{0}$ is the initial value, and $x_{t}^{+}$, and $x_{t}^{-}$are the partial sum processes of positive and negative changes of $x_{t}$ defined as:

$$
\begin{gathered}
x_{t}^{+}=\sum_{j=1}^{t} \Delta x_{j}^{+}=\sum_{j=1}^{t} \max \left(\Delta x_{j}, 0\right) \\
x_{t}^{-}=\sum_{j=1}^{t} \Delta x_{j}^{-}=\sum_{j=1}^{t} \min \left(\Delta x_{j}, 0\right)
\end{gathered}
$$

Where, $x_{t}$ is decomposed into $x_{t}^{+}$and $x_{t}^{-}$around a single threshold value of zero, which allows us to distinguish between positive and negative changes in the growth rate of $x_{t}$. Indeed, introducing the short and long-run asymmetries in the standard ARDL model leads to the following general form of the nonlinear NARDL model:

$$
\Delta y_{t}=\mu+\rho_{y} y_{t-1}+\rho_{x}^{+} x_{t-1}^{+}+\rho_{x}^{-} x_{t-1}^{-}+\sum_{i=1}^{r} \alpha_{i} \Delta y_{t-1}+\sum_{i=0}^{s}\left(\beta_{i}^{+} \Delta x_{t-1}^{+}+\beta_{i}^{-} \Delta x_{t-1}^{-}\right)+\varepsilon_{t}
$$

Table 9 exhibits the asymmetric responses of oil rents per capita, and the ratio of oil production to oil consumption, to gross domestic product per capita, both the short- and long-run in model 1, and short-run in model 2 for the models FE, FE robust (FE Rob.), and FE Driscoll and Kraay (FE D.-K.). 


\begin{tabular}{|c|c|c|c|c|c|c|c|c|}
\hline \multicolumn{9}{|c|}{ Dependent Variable $\triangle$ LYPC } \\
\hline & \multicolumn{4}{|c|}{ Model 1} & \multicolumn{4}{|c|}{ Model 2} \\
\hline & & $\mathrm{FE}$ & $\begin{array}{l}\text { FE } \\
\text { Rob. }\end{array}$ & FE D.-K. & & $\mathrm{FE}$ & $\begin{array}{l}\text { FE } \\
\text { Rob. }\end{array}$ & FE D.-K. \\
\hline Constant & 0.5308 & $* * *$ & $* * *$ & $* * *$ & 0.2808 & $* * *$ & $* * *$ & $* * *$ \\
\hline$\triangle \mathrm{LEPC}$ & 0.2940 & $* * *$ & $* * *$ & $* * *$ & 0.3017 & $* * *$ & $* * *$ & $* * *$ \\
\hline$\Delta \mathrm{LXPC}$ & 0.0381 & $* * *$ & $* *$ & $* * *$ & 0.0363 & $* * *$ & ** & $* * *$ \\
\hline$\Delta$ SO_POS & 0.0154 & $* * *$ & $* * *$ & $* * *$ & 0.0157 & $* * *$ & $* * *$ & $* * *$ \\
\hline$\Delta$ SO_NEG & 0.0243 & $* * *$ & $* * *$ & $* * *$ & 0.0203 & $* * *$ & $* * *$ & $* * *$ \\
\hline$\triangle$ LORPC_POS & -0.0036 & $*$ & $* *$ & & 0.0002 & & & \\
\hline$\Delta$ LORPC_NEG & -0.0039 & & & & -0.0028 & & & \\
\hline$\Delta \mathrm{LP}$ & 0.0118 & $* *$ & & $*$ & 0.0089 & * & & \\
\hline LXPC(-1) & 0.0507 & $* * *$ & $* * *$ & $* * *$ & 0.0457 & $* * *$ & $* * *$ & $* * *$ \\
\hline LSO_POS(-1) & 0.0024 & $* * *$ & $* * *$ & $* * *$ & & & & \\
\hline LSO_NEG(-1) & 0.0013 & $* *$ & & & & & & \\
\hline LORPC_POS(-1) & -0.0033 & $* * *$ & $* * *$ & $* * *$ & & & & \\
\hline LORPC_NEG(-1) & -0.0022 & $* *$ & & $*$ & & & & \\
\hline LP(-1) & & & & & -0.0048 & $* * *$ & $* *$ & \\
\hline \multirow[t]{2}{*}{ ECM } & -0.0693 & $* * *$ & $* * *$ & $* * *$ & -0.0656 & $* * *$ & $* * *$ & $* * *$ \\
\hline & & \multicolumn{3}{|c|}{ Statistics } & & \multicolumn{3}{|c|}{ Statistics } \\
\hline $\mathrm{N}$ & 944 & & 944 & 944 & 944 & & 944 & 944 \\
\hline$R^{2}$ within & 0.4025 & & 0.4025 & & 0.3823 & & 0.3823 & \\
\hline$R^{2}$ between & 0.1560 & & 0.1560 & & 0.1992 & & 0.1992 & \\
\hline$R^{2}$ overall & 0.0561 & & 0.0561 & & 0.2066 & & 0.2066 & \\
\hline $\mathrm{F}$ & 47.15 & $* * *$ & $52.21 * * *$ & $28.87 * * *$ & 56.50 & $* * *$ & $21.55 * * *$ & $37.85 * * *$ \\
\hline
\end{tabular}

Notes: $* * *, * * *, *$ denote statistically significant at $1 \%, 5 \%$, and $10 \%$ level, respectively; and the Stata commands $x$ treg, and $x t s c c$ were used.

Table 10 exhibits the Wald tests of nonlinear hypotheses of asymmetric responses of oil rents per capita, and the ratio of oil production to oil consumption, to gross domestic product per capita, both the short- and long-run in models 1 and 2, for the models FE, FE Rob., and FE FE D.-K.

Table 10. Wald test of nonlinear hypotheses.

\begin{tabular}{llll|llc}
\hline & \multicolumn{3}{c|}{ Model 1 } & \multicolumn{2}{c}{ Model 2 } \\
\cline { 2 - 6 } & FE & FE Rob. & FE D.-K. & FE & FE Rob. & FE D.-K. \\
\cline { 2 - 6 } Short-run & $4.15 * *$ & 1.39 & $2.92 *$ & 1.54 & 1.21 \\
$\beta_{\Delta S O}^{+}=\beta_{\Delta S O}^{-}$ & 0.00 & 0.00 & 0.00 & 0.48 & 0.49 & 0.42 \\
$\beta_{\Delta L O R P C}^{+}=\beta_{\Delta L O R P C}^{-}$ & & & & & \\
Long-run & $5.72 * *$ & 1.71 & $3.06 *$ & & \\
$\rho_{L S O(-1)}^{+}=\rho_{L S O(-1)}^{-}$ & 1.69 & 0.52 & 1.03 & & \\
$\beta_{O R P C(-1)}^{+}=\beta_{O R P C(-1)}^{-}$ & & & & \\
\hline
\end{tabular}

Notes: $* * *, * * * *$ denote statistically significant at $1 \%, 5 \%$, and $10 \%$ level, respectively; and the Stata command testnl was used after the post estimations; results for $H_{0}$ of Wald test of nonlinear hypotheses: equality of parameters. 


\section{5 - Discussion}

The analysis of the effects of the ratio of oil production on oil consumption and oil rents on economic growth for a set of oil-producing countries extend the approach to energy-growth nexus. The results are based on per capita data and for a panel of oil-producing countries in diversified stages of production and with different oil endowments. Indeed, the panel comprises a mixture of developing and developed countries, and small and heavy (OPEC members) oil producers. This variety of countries ensures that the analysis is performed as a general one. Overall, the results point to the presence of cointegration/long memory as the coefficients of the ECM are negative and highly statistically significant.

Several drivers of economic growth were detected. They embody numerous effects, in either the short- or the long-run. Apart from oil rents, the drivers are positive. Oil consumption and international crude prices do not drive growth in the long-run. In general, the exports reveals to be a relevant long-run driver of economic growth. As the causality running from primary energy consumption to economic growth was detected only in the short-run, this suggests the presence of the weak growth hypothesis of the energy-growth nexus. In general, the variables SO and LORPC are substitutes of LP for oil-producing countries. Results reveal that there is a positive effect on economic growth, not only from exports (including oil) and the oil price (this just in the short-run) but also from the ratio of oil production to oil consumption. These effects are expected, and any other indications would be challenging to support. In turn, the observed adverse effect for oil rents deserves particular analysis. Referring to the beginning, this variable comprises the revenues coming from the external sales of oil, but also the cost of extraction

Therefore, when oil extraction costs go down, then the economy experiences a cheaper source of money. This provokes more dependence coming from more inertia in the economy's structure, with less need for diversification of activities. Also, the increase in disposable income in these countries also induces the import of non-productive goods for luxury consumption. This fact further worsens the deficits of these countries and does not contribute to the required diversification of its domestic production structure.

The effect of inertia is persistent in time, even causing an adverse effect in the short-run. This outcome is also consistent with that observed in oil prices. In the short-run, the increase in the international price boosts economic growth, due to the additional revenue's immediate effect. However, in the long-run, this revenue growth effect is more than offset by the effects described, which means that prices are not statistically significant. This outcome could serve as a guideline for the design of energy policies. Indeed, policymakers should be focused on promoting savings from these additional profits, arising from the enhancement of revenues or reductions in costs, for instance in the form of a consigned fund. It could be dedicated exclusively to diversifying the productive structure and to promoting the substitution of imports.

This research also shows a slow ECM, which is consistent with the limited capacity of the economy to recover, not only because of its high dependency on one or only a few sectors but also because these countries do not have competitive environments. This apathy contaminates all sectors of the economy, limiting its responsiveness and reaction to shocks. When shocks occur countries require a long period to return to equilibrium.

The tests of asymmetric responses of the oil rents per capita, and the ratio of oil production to oil consumption, to gross domestic product per capita, in the short- and long-run in model 1 ; and short-run in model 2 , did not confirm the asymmetries.

\section{6 - Conclusion and policy implications}

This paper goes further on the traditional analysis of the energy-growth nexus. Based on a set of oil producing countries, the effects of the ratio of oil production on oil consumption and oil rents on economic growth were examined. The impact was also assessed by controlling both for primary energy consumption and exports, and by exploring a causality analysis within a multivariate energy-growth nexus framework. The results were obtained for a long time span and by using recent panel data estimators that are sensitive to time asymptotic properties. The presence of cross-section dependence was detected, but no cross heterogeneity of parameters' slopes was found. The decomposition of the total effects into their short- and long-run components proved to be worthwhile. Furthermore, the literature on the energy-growth nexus in oil-producing countries benefits from bringing together diverse panel data estimators comparing their outcomes. In the long-run, the variables SO and LORPC are proxies of LP for oil-producing countries. The high internal consistency of the results of this study may even cast doubt on the conclusions of other studies that do not observe evidence for the "resource curse". Indeed, they are often only working on the prices of oil or resources, instead of finding an appropriate measurement of the rents coming from the exploration of the endogenous resources.

Evidence was found, in the short-run, of the traditional growth hypothesis of the energy-growth nexus. As the ECM term is negative and statistically highly significant, the FE panel dynamic specification detected cointegration/long memory. The driving forces of relative oil production, primary energy consumption, and oil rents on growth were established. The ratio of oil production to oil consumption has exerted a positive impact on growth, both in the short- and longrun, emphasising that increasing the oil surplus promotes economic growth. Oil rents depress growth both in the short- and long-run, suggesting that they are more of a curse than a blessing for these economies. 


\section{References}

ALEXEEV, M., CONRAD, R. The elusive curse of oil. The Review of Economics and Statistics, 91(3), pp. 586-598, 2009.

AL-MULALI, U. Oil Consumption, CO2 emission and economic growth in MENA countries. Energy, 36(10), pp. 6165-6171, 2011.

APERGIS, N., PAYNE, J. E. Energy consumption and economic growth in Central America: Evidence from a panel cointegration and error correction model. Energy Economics, 31(2), pp. 211-216, 2009.

BRUNNSCHWEILER, C., BULTE, E. The resource curse revisited and revised: A tale of paradoxes and red herrings. Journal of Environmental Economics and Management, 55(3), pp. 248-264, 2008.

CHOI, H.-Y., YOO, S.-H. Oil consumption and economic growth: The case of Brazil. Energy Sources, Part B: Economics, Planning, and Policy, 11(8), pp. 705-710, 2016.

CHOI, I. Unit root tests for panel data. Journal of International Money and Finance, 20(1), pp. 249-272, 2001.

CORDEN, W., NEARY, J. Booming sector and de-industrialization in a small open economy. Economic Journal, 92(368), pp. 825-848, 1982.

DJELloul, B., TALBI, B. The Impact of Oil Production on Economic Growth in OPEC Countries: Evidence from The Panel Approach. The Journal of Applied Business Research, 33(2), pp. 257-262, 2017.

DRISCOLL, J., KRAAY, A. C. Consistent covariance matrix estimation with spatially dependent data. Review of Economics and Statistics, 80(4), pp. 549-560, 1998

EL-KATIRI, L. Energy sustainability in the Gulf States: the why and the how. Oxford Institute for Energy Studies, 2013 [online] http://www.oxfordenergy.org/wpcms/wp-content/uploads/2013/03/MEP_4.pdf (Accessed 21 January 2014).

FRANKEL, J. The natural resource curse: a survey. NBER Working Paper Series, Working Paper 15836, 2010.

FUINHAS, J. A., MARQUES, A. C., COUTO, A. P. Economic growth and self-consumption in oil producing countries: Empirical evidence and perspectives ,in Accosi, C. (Ed.), Economic Growth in the 21st Century: Perspectives, Role of Governmental Policies, Potential and Constraints. Nova Science Publishers, New York, Chapter 3 , pp. 57-86, 2014.

FUINHAS, J. A., MARQUES, A. C., COUTO, A. P.Oil-Growth Nexus in Oil Producing Countries: Macro Panel Evidence. International Journal of Energy Economics and Policy, 5(1), pp. 148-163, 2015.

ISMAIL, K.The Structural Manifestation of the Dutch Disease: The Case of Oil Exporting Countries. IMF Working Paper WP/10/103, 2010.

LARSEN, E. Escaping the resource curse and the Dutch Disease? When and why Norway caught up with and forged ahead of its neighbors. Discussion Papers No. 377, Statistics Norway, Research Department, 2004

LEVIN, A., LIN, C.-F., CHU, C.-S. J. Unit root test in panel data: Asymptotic and finite-sample properties. Journal of Econometrics, 108(1), pp. 1-24, 2002.

MADDALA, G. S., WU, S. A comparative study of unit root tests with panel data a new simple test. Oxford Bulletin of Economics and Statistics, 61(S1), pp. 631-652, 1999

MENEGAKI, A. N., OZTURK, I. Renewable energy, rents and GDP growth in MENA countries. Energy Sources, Part B: Economics, Planning and Policy, 11(9), pp. 824-829, 2016

NARAYAN, P. K., SMYTH, R. Energy Consumption and Real GDP in G7 Countries: New Evidence from Panel Cointegration with Structural Breaks. Energy Economics, 30(5), pp. 2331-2341, 2008.

OZTURK, I. Measuring the impact of alternative and nuclear energy consumption, carbon dioxide emissions and oil rents on specific growth factors in the panel of Latin American countries. Progress in Nuclear Energy, 100, pp. 71-81, 2017.

OZTURK, I. A literature survey on energy-growth nexus. Energy Policy, 38(1), pp. 340-349, 2010.

PESARAN, M. H. A simple panel unit root test in the presence of cross-section dependence. Journal of Applied Econometrics, 22(2), pp. 265-312, 2007.

ROSS, M. Does Oil Hinder Democracy?. World Politics, 53(3), pp. 297-322, 2001

SABOORI, B., RASOULINEZHAD, E., SUNG, J. The nexus of oil consumption, $\mathrm{CO} 2$ emissions and economic growth in China, Japan and South Korea Environmental Science and Pollution Research, 24(8), pp. 7436-7455, 2017.

SMITH, B. Dutch disease and the oil and boom and bust, OxCarre Research Paper 133. Oxford Centre for the Analysis of Resource Rich Economies, 2014

STRATFOR. When oil prices drop, some countries lose, 2014 [online] http://www.stratfor.com/sample/analysis/when-oil-prices-drop-some-countries-lose (Accessed 3 December 2014).

TORVIK, R. Learning by doing and the Dutch disease. European Economic Review, 45(2), pp. 285-306, 2001.

WESTERLUND, J. Testing for error correction in panel data. Oxford Economics and Statistics, 69(6), pp. 709-748, 2007. 
WOLDE-RUFAEL, Y. Energy Consumption and Economic Growth: The Experience of African Countries Revisited. Energy Economics, 31(2), pp. 217-224, 2009. WORLD BANK. The Changing Wealth of Nations: Measuring Sustainable Development in the New Millennium, Washington DC, 2011.

YILDIRIM, E., SUKRUOGLU, D., ASLAN, A. Energy Consumption and Economic Growth in the Next 11 Countries: The Bootstrapped Autoregressive Metric Causality Approach. Energy Economics, 44, pp. 14-21, 2014

YUAN, C., LIU, S., XIE, N. The Impact of Chinese Economic Growth and Energy Consumption of the Global Financial Crisis: An Input-Output Analysis. Energy, 35(4), pp. 1805-1812, 2010.

ZHANG, X., CHENG, X. Energy Consumption, Carbon Emissions and Economic Growth in China. Ecological Economics, 68(10), pp. 2706-2712, 2009. 